\title{
Prevalence and Risk Factors of Postpartum Depression among Women in a Primary Health Care Unit, Qalyoubia Governorate, Egypt
}

\author{
${ }^{1}$ Mohamed EA, ${ }^{2}$ Sabbour SM, ${ }^{2}$ Abdelhamid MA, ${ }^{2}$ EIBagoury LS. \\ ${ }^{1}$ Family physician specialist, Ministry of health and population. ${ }^{2}$ Community, \\ Environmental and Occupational Medicine Department, Faculty of Medicine, Ain Shams \\ University
}

Submission Date: 2020-01-10 Revision Date: 2020-03-07 Acceptance Date: 2020-03-07

\begin{abstract}
Background: Postpartum depression (PPD) represents a considerable health problem affecting women and their families. Objective: to determine the prevalence and risk factors of postpartum depression among women attending Al- Mostkbal primary health care unit in Al-Obour city. Method: A cross sectional study was conducted including 225 postpartum women selected from Al- Mostakbal primary health care centre in the postpartum period. They were subjected to two forms of questionnaires (1) Edinburgh Postnatal Depression Scale (EPDS), and (2) An interview questionnaire to collect data about possible risk factors of postpartum depressive symptoms. Results: The mean age of studied women was 30.9 years \pm 6.09 . Prevalence of postpartum depression symptoms was found to be $37.78 \%$ according to EPDS using a cutoff point $>12$. These symptoms were significantly higher in the first six months than the second six months after delivery $(\mathrm{P}<0.001)$. Mothers who had their newborns admitted to neonatal intensive care unit (NICU), hospitalization for her newborn, annoyed from weight gain after labour, lack of husband support during or after pregnancy, twins' newborn and a past history of depression were the significant variables associated with PPD symptoms. However, age, employment, pregnancy loss, and preterm labour had no significant association with PPD. Conclusion: Factors that may lead to development of PPD, include some sociodemographic, obstetric, and psychosocial ones. Early detection of these factors may help in prediction of the development of PPD by family physicians.
\end{abstract}

Keywords: postpartum, depression, family physician, primary health care.

Corresponding Author: Dr. Lamyaa Said ElBagoury e-mail: 1s_bagoury@yahoo.com

\section{Introduction}

Postpartum depression (PPD) is a common disorder defined as "any nonpsychotic depressive symptoms occurring during the first postpartum year". ${ }^{1}$ Also is defined as a psychological mood disorder that occurs in a mother within 6 weeks of her giving birth. It is a condition that causes mood disturbance and might begin in, or extend after, the postpartum period. $^{2}$

The negative consequences of PPD are not limited to mothers; PPD also affects the rest of family members and family dynamics. PPD can also lead to significant language, cognitive and emotional developing problems in children. ${ }^{3}$ Husbands are also more likely to get depressed when their wives have PPD. ${ }^{4}$

Postpartum depression affects 10 to $22 \%$ of postpartum women in developed countries $^{5,6}$ and reaches up to $40 \%$ among mothers of preterm infants. ${ }^{7}$ In Turkey, it was estimated to be $15.4 \%{ }^{8}$ Arab women show rates, such as $37 \%$ in Bahrain ${ }^{9}, 22 \%$ in the United Arab Emirates ${ }^{10}$ and $21 \%$ in Lebanon. ${ }^{11}$ 
Some of the identified risk factors are hormonal, social, low self-esteem, life stress, fatigue, prenatal depression, lack of husband support, low socioeconomic status, depression or anxiety during pregnancy, preterm labour and unintended pregnancy. These risk factors predict women who may be at risk. ${ }^{12,13} \mathrm{~A}$ study in 2014 in the Eastern province capital of Saudi Arabia found that the most common risk factors of PPD was stressful life events, followed by a lifetime history of depression and anxiety. ${ }^{14}$ To overcome these significant impediments early detection by family physicians is crucial. The optimal time to screen for PPD is between 2 weeks and 6 months after delivery. ${ }^{15}$ Research has highlighted protective factors which include being within a social support environment, having a supportive spouse, problem-solving ability and access to community-based supports. ${ }^{16}$

Although the disease has many adverse outcomes, it has been found that the majority of the cases of postpartum depression are not detected by healthcare providers. More research studies on postpartum depression are needed, to better understand the disease and its causes, with a highlight on prevention, early diagnosis and treatment. ${ }^{17}$

Family physicians can meet mothers who may come for family planning counselling or for their babies developmental follow ups and immunizations, to actively screen them using the Edinburgh Postnatal Depression Scale (EPDS). Family physicians can manage at-risk mothers by providing them with advice, support, and medication. Mothers with persistent maladjustment can be referred for specialist assessment. ${ }^{18}$

Postpartum depression in mothers of young children represents a public health hazard and highlights the need for further research to improve prevention and management.
Objective: To determine the prevalence and risk factors of post-partum depression among postpartum women attending Al- Mostkbal primary health care unit.

\section{Method}

A cross sectional study was conducted in 2015 among postpartum women at AlMostakbal primary health care center (PHC). The center is located in $\mathrm{El}$ Mostakbal district, El Obour city, Qalyuobia governorate. El Obour city, one of the new urban areas in Greater Cairo, is about 35 kilometers north-east of Cairo and has been constructed in 1995.

Al- Mostakbal primary health care center is one of three primary health care centers in El Obour city. It includes five outpatient clinics: pediatric and internal medicine, dental, ophthalmology, gynecological and obstetric, and family planning clinic, in addition to a laboratory. The center was chosen conveniently to conduct the study.

Calculation of the sample size was based on the prevalence rate of PPD in a study done in Mansoura city, Egypt ${ }^{19}$, and on the following assumptions using EZR Stata program [R version 3.3.1 (2016-0621)]: Alpha error $=0.05$ (two sided), $\mathrm{p}=0.17$ for PPD, where $\mathrm{p}$ is the proportion of PPD among Egyptian women, confidence interval width $=0.1$, and confidence level $=95 \%$. Accordingly, the sample size was estimated to be at least 217 postpartum women. Sampling method: systematic random sampling.

Any woman in the postpartum period (two weeks up to 12 months after labor) who is seeking to receive any of the PHC center services e.g. vaccination, family planning, outpatient clinic, and accepted to participate in the study.

Pregnant women, presence of any chronic disease either mental or physical, presence of any psychiatric disorder at 
A verbal consent was taken from all participants after describing the

objectives of the research;

Table (2): Univariate analysis of demographic risk factors for postpartum depression among studied sample (total $=225$ )

\begin{tabular}{|c|c|c|c|c|c|c|c|}
\hline & \multicolumn{4}{|c|}{ Groups } & \multirow{3}{*}{ OR (95\% C.I.) } & \multirow{2}{*}{\multicolumn{2}{|c|}{ Chi-square test }} \\
\hline & \multicolumn{2}{|c|}{$\begin{array}{c}\text { Positive } \\
\text { screened } \\
\text { women } \\
(n=85)\end{array}$} & \multicolumn{2}{|c|}{$\begin{array}{c}\text { Negative } \\
\text { screened } \\
\text { women } \\
(n=140)\end{array}$} & & & \\
\hline & No. & $\%$ & No. & $\%$ & & $\mathbf{x}^{2}$ & p-value \\
\hline \multicolumn{8}{|l|}{ Age (years) } \\
\hline$<20$ years & 5 & 83.33 & 1 & 16.67 & $8.42(0.95,74.81)$ & \multirow{3}{*}{5.485} & \multirow{3}{*}{0.064} \\
\hline $20-30$ years & 42 & 35.90 & 75 & 64.10 & $0.94(0.54,1.64)$ & & \\
\hline$>30$ years & 38 & 37.25 & 64 & 62.75 & 1 (ref.) & & \\
\hline \multicolumn{8}{|l|}{ Education level } \\
\hline Illiterate & 7 & 77.78 & 2 & 22.22 & $6.893(1.36,35.06)$ & \multirow{5}{*}{14.329} & \multirow{5}{*}{$0.014 *$} \\
\hline Read and write & 9 & 64.29 & 5 & 35.71 & $3.545(1.1,11.43)$ & & \\
\hline Primary education & 8 & 30.77 & 18 & 69.23 & $0.875(0.34,2.22)$ & & \\
\hline Secondary education & 28 & 35.90 & 50 & 64.10 & $1.103(0.59,2.06)$ & & \\
\hline High education & 33 & 33.67 & 65 & 66.33 & 1 (ref.) & & \\
\hline \multicolumn{8}{|l|}{ Employment } \\
\hline Housewife & 35 & 47.95 & 38 & 52.05 & $115(1.11,4.03)$ & \multirow{3}{*}{5.820} & \multirow{3}{*}{0.213} \\
\hline Private & 23 & 36.51 & 40 & 63.49 & $320(0.67,2.62)$ & & \\
\hline Governmental & 27 & 30.34 & 62 & 69.66 & (ref.) & & \\
\hline \multicolumn{8}{|l|}{ Marital status } \\
\hline Currently married & 65 & 32.50 & 135 & 67.50 & $0.120(0.04-0.34)$ & \multirow{2}{*}{5.151} & \multirow{2}{*}{$0.002 *$} \\
\hline Separate /widow & 20 & 80.00 & 5 & 20.00 & 1 (ref.) & & \\
\hline \multicolumn{8}{|l|}{ Family type (Living) } \\
\hline Nuclear family & 64 & 44.14 & 81 & \multirow{2}{*}{\multicolumn{2}{|c|}{$\begin{array}{l}55.862 .219(1.22-4.03) \\
73.751 \text { (ref.) }\end{array}$}} & \multirow{2}{*}{6.278} & \multirow{2}{*}{ 0.012* } \\
\hline With extended family & 21 & 26.25 & 59 & & & & \\
\hline
\end{tabular}

\section{*Statistically significant}

and privacy of data were ensured. Approval of the Research Ethical Committee in the Faculty of Medicine, Ain Shams University was obtained. Written approval was taken from the center administration and was signed by the doctor director of the primary healthcare center.

\section{Results}

A total of 225 postpartum women were selected for the study. Their mean age was 30.9 years with a standard deviation of 6.09 and ranging from 18 to 44 years. Table (1) shows that the prevalence of depressive symptoms among the studied postpartum women was $37.78 \%$ (as $34.22 \%$ and $3.56 \%$ of women had scores above 12), according to EPDS, with a minimum score of four and a maximum of 21 . The mean score was 11.64 and the standard deviation was 4.91 .
Table (2) shows that the studied postpartum women who are illiterate or can just read and write, those who are separated from their husbands or widowed, and those who live in a nuclear family, have significantly high risk for postpartum depressive symptoms than those who are not. Age and employment of women didn't show significant association with postpartum depression.

In table (3), postpartum women who lack husband support, and those who have past or family history of depression have significantly high risk for postnatal depression than those who are not. Smoking showed no association with postpartum depression symptoms.

As regard obstetric risk factors shown in table (4), multiparity, delivery of multiple newborns (twin), unintended pregnancy, presence of diseases during or after pregnancy, mother being annoyed from weight gain, having delivered by caesarian section, and 
admission of the newborn to ICU or hospital, are all factors that showed significant association with postpartum

Table (3): Univariate analysis of social risk factors for postpartum depression among studied sample (total=225)

\begin{tabular}{|c|c|c|c|c|c|c|c|}
\hline & \multicolumn{4}{|c|}{ Groups } & \multirow{3}{*}{$\begin{array}{c}\text { OR } \\
(95 \% \text { C.I. })\end{array}$} & \multirow{2}{*}{\multicolumn{2}{|c|}{ Chi-square test }} \\
\hline & \multicolumn{2}{|c|}{$\begin{array}{c}\text { Positive screened } \\
\text { women } \\
(\mathbf{n}=85) \\
\end{array}$} & \multicolumn{2}{|c|}{$\begin{array}{c}\text { Negative screened } \\
\text { women } \\
(n=140) \\
\end{array}$} & & & \\
\hline & No. & $\%$ & No. & $\%$ & & $\mathrm{x}^{2}$ & p-value \\
\hline $\begin{array}{l}\text { Smoking during or } \\
\text { after pregnancy }\end{array}$ & 2 & 40.00 & 3 & 60.00 & $1.100(0.18-6.72)$ & 2.403 & 0.121 \\
\hline $\begin{array}{l}\text { Lack of husband } \\
\text { support }\end{array}$ & 45 & 48.39 & 48 & 51.61 & $0.469(0.27-0.81)$ & 7.362 & $0.007 *$ \\
\hline History of depression & 9 & 69.23 & 4 & 30.77 & $5.026(1.20-13.51)$ & 5.807 & 0.016* \\
\hline $\begin{array}{l}\text { Family history of } \\
\text { depression }\end{array}$ & 10 & 62.50 & 6 & 37.5 & $2.978(1.04-8.52)$ & 4.479 & 0.043* \\
\hline
\end{tabular}

depression in the studied sample. Among those in the first six

Table (4): Univariate analysis of obstetric risk factors for postpartum depression among studied sample (total $=225$ )

\begin{tabular}{|c|c|c|c|c|c|c|c|}
\hline & \multicolumn{2}{|c|}{$\begin{array}{c}\text { Positive } \\
\text { screened } \\
\text { women } \\
(\mathbf{n}=85)\end{array}$} & \multicolumn{2}{|c|}{$\begin{array}{c}\text { Negative } \\
\text { screened women } \\
\quad(n=140)\end{array}$} & \multirow[t]{2}{*}{$\begin{array}{c}\text { OR } \\
\text { (95\% C.I.) }\end{array}$} & \multirow[b]{2}{*}{$\mathrm{x}^{2}$} & \multirow[b]{2}{*}{ p-value } \\
\hline & No. & $\%$ & No. & $\%$ & & & \\
\hline \multicolumn{8}{|l|}{ Parity } \\
\hline Primipara & 14 & 29.79 & 33 & 70.21 & \multirow{2}{*}{$\begin{array}{c}0.64 \text { (0.32-1.27) } \\
1 \text { (ref.) }\end{array}$} & \multirow{2}{*}{4.481} & \multirow{2}{*}{$\mathbf{0 . 0 2 3}^{*}$} \\
\hline Multipara & 71 & 39.89 & 107 & 60.11 & & & \\
\hline $\begin{array}{l}\text { Delivery of multiple } \\
\text { newborns (twin) }\end{array}$ & 10 & 66.67 & 5 & 33.33 & $3.60(1.19-10.92)$ & 4.667 & $0.032 *$ \\
\hline $\begin{array}{l}\text { Unintended } \\
\text { pregnancy }\end{array}$ & 50 & 33.78 & 98 & 66.22 & $0.612(0.35-1.08)$ & 4.935 & $0.047 *$ \\
\hline $\begin{array}{l}\text { Diseases during or } \\
\text { after pregnancy }\end{array}$ & 30 & 58.82 & 21 & 41.18 & $3.09(1.62-5.88)$ & 12.427 & $0.001 *$ \\
\hline $\begin{array}{ll}\text { History } & \text { of } \\
\text { pregnancy loss } & \\
\end{array}$ & 30 & 46.15 & 35 & 53.85 & $1.64(0.91-2.94)$ & 3.314 & 0.069 \\
\hline $\begin{array}{ll}\text { Annoyed } & \text { from } \\
\text { weight gain } & \\
\end{array}$ & 70 & 43.75 & 90 & 56.25 & $2.59(1.35-4.99)$ & 7.541 & $0.006^{*}$ \\
\hline \multicolumn{8}{|l|}{ Mode of delivery } \\
\hline $\begin{array}{l}\text { Normal delivery } \\
\text { Caesarian section }\end{array}$ & $\begin{array}{l}45 \\
40\end{array}$ & $\begin{array}{l}31.69 \\
48.19\end{array}$ & $\begin{array}{l}97 \\
43\end{array}$ & $\begin{array}{l}68.31 \\
51.81\end{array}$ & $\begin{array}{c}0.49(0.29-0.87) \\
1 \text { (ref.) }\end{array}$ & 6.069 & $0.014 *$ \\
\hline Preterm labour & 6 & 66.67 & 3 & 33.33 & $3.468(0.84-14.25)$ & 2.177 & 0.140 \\
\hline $\begin{array}{l}\text { Newborn } \\
\text { incubation, } \\
\text { hospitalization }\end{array}$ & 29 & 48.33 & 31 & 51.67 & $1.82(0.99-3.32)$ & 3.878 & $0.049 *$ \\
\hline \multicolumn{8}{|l|}{ Postpartum interval } \\
\hline $1^{\text {st }}$ six months & 75 & 78.95 & 20 & 21.05 & 45 (19.9-101.3) & \multirow{2}{*}{115.547} & \multirow{2}{*}{$<0.001 *$} \\
\hline $2^{\text {nd }}$ six months & 10 & 7.69 & 120 & 92.31 & 1 (ref.) & & \\
\hline $\begin{array}{l}\text { *Statistically sigr } \\
\text { months after deliv } \\
\text { found positive for } \\
7.69 \% \text { in the second } \\
\text { difference was foun } \\
(\mathrm{p}=0.001) \text {. Whereas }\end{array}$ & $\begin{array}{l}\text { ificant } \\
\text { ery, } 7 \\
\text { PPD, } \\
\text { six mo } \\
\text { d to b } \\
\text { history }\end{array}$ & $\begin{array}{l}5 \% \\
\text { npare } \\
\text { ss, and } \\
\text { signifi } \\
\text { pregn }\end{array}$ & $\begin{array}{l}\text { were } \\
\text { ed to } \\
\text { d the } \\
\text { ficant } \\
\text { icancy }\end{array}$ & $\begin{array}{l}\text { loss } \\
\text { show } \\
\text { cond } \\
\text { Nine } \\
\text { foun }\end{array}$ & $\begin{array}{l}\text { and having a prete } \\
\text { significant asso } \\
\text { ition. } \\
\text { out of } 13 \text { stressfu } \\
\text { significant r }\end{array}$ & $\begin{array}{l}\text { m labou } \\
\text { iation } \\
\text { life eve } \\
k \text { fact }\end{array}$ & $\begin{array}{l}\text { Ir did not } \\
\text { with the } \\
\text { ents were } \\
\text { tors for }\end{array}$ \\
\hline
\end{tabular}


occurrence of PPD. These are: severs illness of a close one, major change in finances, increase arguments with

Table (5): Multivariate logistic regression analysis of risk factors for postpartum depression among studied sample (total $=225$ )

Major change in finances

History of depression

Delivery of multiple newborns (twin)

Family history depression

Annoyed from weight gain after labour

Living in a nuclear family

NICU admission or hospitalization

Multiparity

Lack of husband support

Unintended pregnancy * Statistically significant

change in residence, change in religious activities, and change in social activities (data not shown in tables).

The multivariate logistic regression analysis in table (5) revealed eight risk factors for postpartum depression, which are: major change in finances, past history of depression, delivery of multiple newborns (twin), family history of depression, mother being annoyed from weight gain, living in a nuclear family, admission of the newborn to ICU or hospital, and lack of husband support.

\section{Discussion}

By using the (EPDS) in the current study, the prevalence of postpartum depressive symptoms was $37.78 \%$. The scale was originally designed to screen rather than to diagnose postnatal depression. This rate highlight the importance of postnatal depression as a public health problem in the community of El Obour city, Qalyoubia Governorate.

The prevalence rate in this study is higher than a previous study in Egypt conducted on 120 postpartum women in Mansoura city, Dakahlia Governorate, $(17.9 \%)$. In that study, women were diagnosed using the Diagnostic and Statistical Manual of Mental Disorders, fourth edition, text revision (DSM IVTR) for major depression with postpartum onset. The diagnosis was spouse, work problems, change in work responsibilities, change in work hours,

\begin{tabular}{|c|c|c|c|}
\hline t & & & Sig. \\
\hline 8.039 & 4342 & 14882 & $<0001 *$ \\
\hline 5.026 & 1.04 & 8.52 & 0.016* \\
\hline 3.600 & 1.186 & 10.924 & $0.024 *$ \\
\hline 2.978 & 1.199 & 13.51 & $\mathbf{0 . 0 4 3}^{*}$ \\
\hline 2.593 & 1.345 & 4.996 & 0.004* \\
\hline 2.220 & 1.223 & 4.029 & $0.009 *$ \\
\hline 1.821 & 0.999 & 3.319 & $\mathbf{0 . 0 5 0}$ * \\
\hline 0.639 & 0.32 & 1.28 & 0.206 \\
\hline 0.469 & 0.27 & 0.81 & $0.007 *$ \\
\hline 0.161 & 0.349 & 1.075 & 0.088 \\
\hline
\end{tabular}

further confirmed by the (EPDS), using the 13 cut-off score in detecting depression, ie, EPDS $\geq 13$ indicates depressive disorder ${ }^{19}$ and this might be the cause of the difference in rates if compared with the current study. However, a higher rate $(49.5 \%)$ than the current study was reported in a village in El- Minia in 2014 on 200 postpartum women. ${ }^{23}$ The study was a community based one and included women up to 14 months postpartum, while the present study is a health-facility one and included women only up to 12 months after delivery.

Previous studies have reported prevalence rates for post-partum depression that affects 10 to $22 \%$ of postpartum women in developed countries 5,6 and reaches up to $40 \%$ among mothers of preterm infants. ${ }^{7}$ In Turkey, it was estimated to be $15.4 \% .^{8}$ Arab women show rates, such as $37 \%$ in Bahrain ${ }^{9}, 22 \%$ in the United Arab Emirates $^{10}$ and $21 \%$ in Lebanon. ${ }^{11}$ Comparisons with other studies are compromised by the variations in the timing of follow-up and using different EPDS thresholds.

Variation in the prevalence rate of PPD among different countries is mostly based on two observations. First, the countries cultural and varied socioeconomic factors, and second is the 
variability of cut-off scores of EPDS used in different settings. ${ }^{13}$ In addition, the sample size and sampling methods share in the variation of prevalence rates. $^{24}$

In the current study the relation between presence of depressive symptoms and age groups was statistically insignificant. This finding was consistent with a cross sectional study on 379 women in Egypt by Saleh et al. who found that no association between age and PPD. ${ }^{19}$ On the other hand, a study by Wolf et al. on 1256 women in two Latin American countries considered young age as a risk factor for puerperal depression. ${ }^{25}$

In this study, there was a statistically significant relation between presence of depressive symptoms and various socioeconomic characteristics like level of education. It was found that $(77.8 \%)$ of those who are illiterate and $(64.3 \%)$ of those who can just read and write, were positive for PPD, compared with lower percentages of groups with higher educational levels. This result is consistent with that of Grussu et al. ${ }^{26}$, and Goyal et al. who found that women with low income, low level of education, unmarried, and unemployed were much more likely than women with no socioeconomic risk factors to have higher depression scores in early postpartum period. ${ }^{27}$

The present study revealed no significant relation between presence of depressive symptoms and unemployment. Most women in the Egyptian society are supported financially by their husbands or families, so unemployment would not represent a stress on the mother. In contrast, a cross-sectional study was conducted in five large primary healthcare centers in Dammam and found a significant relation between unemployment and PPD. ${ }^{14}$

Regarding marital status, statistically significant relation was shown between divorce or marital separation and presence of depressive symptoms as
$(80 \%)$ of separated or widowed women screened positive for PPD versus $(32.5 \%)$ of those married at the time of the study. A meta-analysis by the National Mental Health Association (2005) concluded that divorce and having troubles with a spouse is one of the strongest risk factors for postpartum depression. $^{28}$

The current study shows no association between smoking and presence of depressive symptoms. Smoking in our society is mainly associated with male gender and it is a shame for women to smoke. On the contrary, McCoy and Jane found that cigarette smoking was a significant risk factor for PPD. ${ }^{29}$ Also, the MGH Center For Women's Mental Health reported an association between PPD and smoking. ${ }^{30}$ The difference in finding between the current study and the two previous studies may be due to the small number of smoker women (five) in the current study.

Regarding husband support, the current study showed a statistically significant relation between lack of husband support and presence of depressive. This result is consistent with Alasoom and Koura who revealed that a supportive husband had a significant role in protection against PPD. ${ }^{14}$

In the current study $78.95 \%$ of women in their first six months after delivery were positive screened for PPD while only $7.69 \%$ of those in their second six months postpartum were positive for PPD and the difference was statistically significant. This finding agrees with a previous study in Egypt by Saleh et al. who found that $98 \%$ of depressed postpartum women were in the first six months after delivery. ${ }^{19}$ A cross-sectional study on a sample of 150 postpartum women in the Perth metropolitan region of Western Australia found that the younger the mothers' babies the higher the level of PPD. ${ }^{2}$ The high prevalence rate at that time may be explained that women are very loaded with infant cues, 
change in sleep pattern, housekeeping and work. In the second six months, infants become less dependent and have regular sleep.

Regarding parity, a statistically significant relation between multiparity and presence of depressive symptoms was present. This finding is confirmed with Shoeb and Hassan in Saudi Arabia ${ }^{31}$ and Esquivel et al. in Mexico ${ }^{32}$, who revealed that having more children associated with higher EPDS scores. Another study has found that primipara are riskier for postpartum depression. ${ }^{33}$ This could be explained as newly married women are likely to spend the first few years of their marriage with the extended family, where there is considerable support. The couples are likely to leave apart from the extended family after a few years of marriage when they have more children and are becoming more independent financially, thus the mother becomes less supported during pregnancy and after delivery.

A statistically significant relation was found between presence of diseases during or after pregnancy and occurrence of depressive symptoms. This result is consistent with a study in Norway, which reported that diseases during and after pregnancy is significantly associated with postpartum depressive symptoms. ${ }^{34}$ A statistically significant relation between presence of depressive symptoms and being annoyed from weight gain during or after pregnancy was found in the present study. This result is consistent with that of a study providing a significant relationship between high BMI and symptoms of depression in the postpartum period. ${ }^{35}$

The current study revealed a statistically significant relation between presence of depressive symptoms and mode of delivery, as $(48.2 \%)$ of women delivered by caesarian section screened positive for PPD versus $(31.7 \%)$ of those delivered normally. This result is consistent with Yang et al. who conducted a case control study in Taiwan on 2107 postpartum women and revealed that the risk of acquiring PPD was lower in mothers with a normal vaginal delivery compared to mothers with caesarean section. ${ }^{36}$ On the other hand, Goker et al. revealed no association between PPD and delivery type. $^{37}$

Regarding multiple births, the current study showed a statistically significant relation between delivering multiple births (twins) and presence of depressive symptoms. This finding is confirmed by Glazebrook et al. who revealed that multiple births associated with increased risk of postpartum depression. ${ }^{38}$ This may be due to the high levels of child caring stress, fatigue and other risk factors that have been reported by mothers of multiple births.

The current study revealed a statistically significant relation between stressful life events (e.g severe illness of a close one, major change in finances and increase arguments with spouse) and presence of depressive symptoms. The psychosocial life stress is a powerful predicator for PPD. $^{13,} 39$ This result is confirmed by Alasoom and Koura who revealed that the most common risk factor for PPD were stressful life events. ${ }^{14}$

\section{Conclusion}

The magnitude of postpartum depression is considerable among the population of women in reproductive age living in $\mathrm{El}$ Obour City, Qalyoubia Governorate. Several demographic, social, obstetric, and medical risk factors are associated with the condition.

\section{Recommendations:}

Findings from the current study recommends adoption of a postpartum depression prevention and control program by family physicians and nurses. Primary prevention strategies, as health education, should be considered in order to decrease the incidence of PPD through reducing risk factors. Secondary prevention is important by early 
identification of PPD mothers especially in the first six months, through using EPDS as a screening tool in primary health care and family centres. This would allow early treatment and protection from subsequent effects on mothers, their babies, and their whole families.

Limitations: This study is a single center, and health facility based not a community based one. Data could be generalized on similar populations as El Obour City, but not on the whole country.

\section{References}

1. Cohen LS, Wang $B$ and Nonacs $R$. Treatment of mood disorders during pregnancy and postpartum. Psychiatr Clin North Am. 2010; 82:926-933.

2. Saligheh M, Rooney RM, McNamara B and Kane RT. The relationship between postnatal depression, socio-demographic factors, levels of partner support, and levels of physical activity. Front Psychol 2014; 5:597:1-8.

3. Bagner D, Pettit J, lewinsohn $\mathrm{P}$ and Seeley J. Effect of maternal depression on child behavior: A sensitive period. Journal of the American academy on child and adolescent psychiatry 2010; 49 (7):699-707. 4. Kessler RC. Epidemiology of women and depression. J. Affect Disord 2003; 74: 5-13.

5. Chew-Graham

CA, Sharp

D, Chamberlain E, Folkes L, Turner KM. Disclosure of symptoms of postnatal depression, the perspectives of health professionals and women: a qualitative study. BMC Family Practice 2009; 10:7.

6. Helbreich U and Karkun S: Cross-cultural and social diversity of prevalence of postpartum depression and depressive symptoms. Journal of Affective Disorders 2006; 91:97-111.

7. Vigod SN, Villegas L, Dennis CL and Rose LE. Prevalence and risk factors of postpartum depression among women with preterm and low- birth - weight infants: a systematic review. BJOG 2010; 117 (5); 540-50.

8. Kirpinar S, GözümT and Pasinlioğlu. Prospective study of postpartum depression in eastern Turkey prevalence: sociodemographic and obstetric correlates prenatal anxiety and early awareness. J Clin. Nurs 2010; 19 (20): 422-431.

9. Al Dallal FH and Grant IN. Postnatal depression among Bahraini women. East Mediterr Health J. 2012; 18 (5):439-445.

10. Green K, Broome $\mathrm{H}$ and Mirabella J. Postnatal depression among mothers in the United Arab Emirates: Socio-cultural and physical factors. J Psychol Health Med 2006; 11:425-431.

11. Chaaya M, Campbell OM, El Kak F, Shaar D, Harb H and Kaddour A. Postpartum depression: prevalence and determinants in Lebanon. J Arch Women Ment Health 2002; $5(2): 65-72$.

12. Beck C.T. Postpartum depression: Stopping the thief that steals motherhood. J Lifelines 1999; 3: 41-44.

13. Beck C.T. Predictors of Postpartum Depression: An Update. J Nursing Research 2001; 50: 275-85.

14. Alasoom LI and Koura MR. Predicators of postpartum depression in eastern province capital of Saudi Arabia. J family Med Prim care 2014; (2):146-150.

15. Pearlstein T, Howard M, Salisbury A and Zlotnick C. Postpartum depression. Am J Obstet Gynecol 2009; 200 (4):357-364.

16. Jung V, Short R, Letourneau $\mathrm{N}$ and Andrews D. Interventions with depressed mothers and their infants: modifying interactive behaviours. Journal of Affective Disorders 2007; 98:199-205.

17. Johnson R, Chapman G, Murray D, Johnson I and Cox J. The North Staffordshire Maternity Hospital prospective study of pregnancy-associated depression. Journal of Psychosomatic Obstetrics and Gynecology 2015; 21: 93-97.

18. Umboh SJ, How $\mathrm{CH}$ and Chen $\mathrm{H}$. Postnatal depression: A family medicine perspective Singapore Med J 2013; 54 (9):477-481.

19. Saleh E, Wafaa El-Bahei, Mohamed A Del El-Hadidy, and Abdelhady Z. Predictors of postpartum depression in a sample of Egyptian women. J Neuropsychiatr Dis Treat 2013; 9: 15-24.

20. Boyce P, Stubbs J and Todd A. The Edinburgh Postnatal Depression Scale: validation for an Australian sample. Aust N Z J Psychiatry 1993; 27:472-476.

21. Ghubash R and Abou-Saleh MT. Postpartum psychiatric illness in Arab culture: prevalence and psychosocial 
correlates. British Journal of Psychiatry 1997; 171: 65-68

22. Cox JL, Holden JM and Sagovsky R. Detection of postnatal depression: development of the 10-item Edinburgh Postnatal Depression Scale. Br J Psychiatry 1987; 150:782-786.

23. Mohammed ES, Mosalem FA, Mahfouz EM and Abd ElHameed MA. Predictors of postpartum depression among rural women in Minia, Egypt: an epidemiological study. Public Health 2014; 128 (9):817-824.

24. Eberhard-Gran, K Slinning and M Rognerud. Screening for postnatal depression : a summary of current knowledge. J Tidsskr Nor Legeforen 2014; 134:297-301.

25. Wolf AW, De Andraca and Lozoff B. Maternal depression in three Latin American samples. J Psychiatr Epidemiol 2002; 37 (4):169-76.

26. Grussu P, Classes O and Quatraro RME. Prevalence and risk factors for a high level of postnatal depression symptomatology in Italian women: a sample drawn from antenatal classes. Eur Psychiatry 2009; 24(5):327-333.

27. Goyal D, Gay C, and Lee KA. How much does low socioeconomic status increase the risk of prenatal and postpartum depressive symptoms in first-time mothers? Women's Health Issues 2010; 20(2): 96-104. 28. National Mental Health Association. Postpartum Disorders 2005. Available online at: http://www.nmha.org. (Accessed June 4, 2013).

29. McCoy SJ and Jane C. Risk Factors for Postpartum Depression: A Retrospective Investigation at 4-Weeks Postnatal and a Review of the Literature. The Journal of the American Osteopathic Association 2006; 106:193-198.

30. MGH Center for Women's Mental Health. Postpartum Psychiatric Disorders. J Nerv Ment Dis 2015;203 (3):164-166.
31. Shoeb IH and Hassan GA. Post-partum psychosis in the Assir Region of Saudi Arabia. Br J Psychiatry 2000; 157:424-430. 32. Esquivel CA, Alvarez AS, Martinez CS and Garcia SM. Validation of the Edinburgh postpartum depression scale in a population of puerperal women in Mexico. Clinical Practice and Epidemiology in Mental Health 2006; 2:33.

33. Kheirabadi GR, Maracy MR and Barekatain M. Risk factors of postpartum depression in rural areas of Isfahan Province, Iran. J Arch Iran Med 2009; 12 (5):461-467.

34. Glavin K, Smith L, Sorum R and Ellefsen B. Redesigned community postpartum care to prevent and treat postpartum depression in women - a oneyear follow-up study. J Clin Nurs 2010; 19 (21-22):3051-3062.

35. La Coursiere Y, Baksh L, Bloebaum L and Vamer M. Maternal body mass index and self-reported postpartum depressive symptoms. Child Health J 2006; 10 (9):385390.

36. Yang SN, Shen LJ, Ping T, Wang YC and Chien CW. The delivery mode and seasonal variation are associated with the development of postpartum depression. $\mathrm{J}$ Affect Disord 2011; 132(1-2):158-64.

37. Goker A, Yanikkerem E, Demet MM, Dikayak S, Yildirim Y, and Koyuncu FM. Postpartum depression: is mode of delivery a risk factor? ISRN Obstet Gynecol 2012; 2012:616759.

38. Glazebrook C, Sheard C, Cox S, OatesM and Ndukwe G. Parenting stress in first-time mothers of twins and triplets conceived after in vitro fertilization. Orcid Fertility and Sterility J 2011: 81 (3): 505-511.

39. Manuel K, Jnnifer K, Melissa LM, Sarah EB and Jennifer LB. The Influence of Stress and Social Support on Depressive Symptoms in Mothers with Young Children.J Social Science and Medicine 2012; 75(11): 20132020. 